Agricultural Journal 5 (2): 70-73, 2010

ISSN: $1816-9155$

(C) Medwell Journals, 2010

\title{
Effects of Basal Fertilizer Applied Technology on Phenophase and Quality of Yield in Cabernet Sauvignon Grape Cultivar
}

\author{
Li Mei, Lu Xiu-Lan, Wang Yong-Qing, Gong Rong-Gao, \\ Deng Qun-Xian, Liao Ming-An and Qin Wen \\ Sichuan Key Laboratory of Ecological Forestry Engineering and \\ Key Laboratory of Horticultural Plant Improvement, \\ Sichuan Agricultural University, Ya'an, 625014 Sichuan, China
}

\begin{abstract}
In the arid and semi-arid habitat in Mao County in the upstream of Min River, we have performed a 5 years experiment on Cabernet Sauvignon grape cultivar exploring 8 technological approaches applying the autumn basal fertilizer. The results show that D handling (stripy furrows storing fertilizer and water plus plastic mulching) made phenophase ahead of time, with 9-13 days in germination stage, 9-15 days in new shoot growing stage, 8-10 days in initial flowering stage and 6-9 days in fruit maturation stage. Meanwhile, the yield was $1637 \mathrm{~kg} / 667 \mathrm{~m}^{2}$ with the increasing percentage of $19.66 \%$, the total sugar content was $20.34 \mathrm{~g} / 100 \mathrm{~g}$ FW with the increasing percentage of $15.57 \%$, tartaric acid content was $0.592 \mathrm{~g} / 100 \mathrm{~g} \mathrm{FW}$ with the decreasing percentage of $15.55 \%$ and the highest anthocyanin content was $78.32 \mathrm{mg} / 100 \mathrm{~g}$. E (two cave fertilizer) produced least, with the lowest production of $1321 \mathrm{~kg} / 667 \mathrm{~m}^{2}$ and the lowest total sugar content of $17.30 / 100 \mathrm{~g} \mathrm{FW}$. E and C (stripy furrows storing fertilizer and water and plant grass) produced the highest tartaric acid content, reaching 0.694 and $0.701 \mathrm{~g} / 100 \mathrm{~g} \mathrm{FW}$, with no distinct differences in tartaric acid content. Then D and $\mathrm{H}$ (two cave storing fertilizer and water plus plastic mulching) produced the lowest tannin content, respectively reaching 0.73 and $0.75 \mathrm{~g} \mathrm{~L}^{-1}$, with no significant differences in tannin content. Besides, there were no evident effects of other fertilizer application techniques on tannin. There was high vitamin $\mathrm{C}$ content among $\mathrm{C}, \mathrm{D}, \mathrm{F}$ (two cave fertilizer and plastic mulching) and $\mathrm{H}$, with no obvious differences.
\end{abstract}

Key words: Cabernet Sauvignon, basal fertilizer, cave storing fertilizer and water, phenophase, yield, quality

\section{INTRODUCTION}

Cabernet Sauvignon grape originates in France and belongs to European subspecies. Currently, the cultivated area of Cabernet Sauvignon grape in China has surpassed $23,000 \mathrm{hm}^{2}$ and it has become the first main cultivated wine grape in the country. The grape has been introduced into the arid and semi-arid area in the upper reaches of the Min River in Mao County (Sichuan Province, China) since 2001 .

The grape has a short growing period, high yield and good quality; specifically a average yield of $300-400$ $\mathrm{kg} / 666.7 \mathrm{~m}^{2}$ in its 2 nd year, $700-900 \mathrm{~kg} / 666.7 \mathrm{~m}^{2}$ in its $3 \mathrm{rd}$ year and steady $1300 \mathrm{~kg} / 666.7 \mathrm{~m}^{2}$ afterwards. The range of soluble solids in the grape is $22.5-25.5 \%$.

The quality grape is purchased by companies at 10.4 Yuan $\mathrm{kg}^{-1}$. However, fertilizer and water in the arid and semi-arid region are scarce and a large part of them are wasted because the famers are unfamiliar with fertilizer conservation and water saving technices and instead employ relatively outdated cultivation management methods such as flood irrigation. Cave storing fertilizer water would save fertilizer, water and provide steady supply of fertilizer in the whole year. It could also reduce labor costs by $30-50 \%$. In the past several years, technologies such as cave storing and plastic mulching are widely applied increase production and quality.

Through scientific research and by guiding local farmers, fertilizer and water waste problems in Cabernet Sauvignon grape growing and the related expensive labor force cost in Mao country have been dealt with. Basal fertilizer applying technology, including stripy furrows to store fertilizer, two cave fertilizer and so on in different locations are being studied. By finding their effects on phenophase, yield and quality in Cabernet Sauvignon grape, we can provide guidance to popularize the standardized, high-efficiency cultivation technology of wine grape.

Corresponding Author: Li Mei, Sichuan Key Laboratory of Ecological Forestry Engineering and Key Laboratory of Horticultural Plant Improvement, College of Foresty, Sichuan Agricultural University, Ya'an, 625014 Sichuan, China 


\section{MATERIALS AND METHODS}

Field area: Two of 5 years old Cabernet Sauvignon graperies, one in Tongheba Village, Mao County and the other in Chibusu Village, Mao County.

Experimental subjects: In two villages, choose Cabernet Sauvignon trees are chosen as the subjects. The subjects are under the same soil fertilizer power of the same gestures of trees and of the same age of 5 years old.

Fertilization treatment: Basal fertilizer was applied in autumn from 2006-2007 (during the last 10 days of October). Stripy furrows fertilization: depth and width of furrow are both $40 \mathrm{~cm}$. Cave applying fertilizer; depth and width of cave are both $40 \mathrm{~cm} / 10 \mathrm{~kg}$ pig-cow-horse stable manure or $1 \mathrm{~kg}$ dried poultrymanure, $0.05 \mathrm{~kg}$ car amide and $5 \mathrm{~kg}$ water will be applied to each plant and the method of planting grass and plastic mulching are also used. The stripy furrows fertilization and two cave fertilizer are used in place of the conventional basal fertilizer. Each plant uses cave storing fertilizer and water to apply fertilizer, $15-20 \mathrm{~cm}$ under water, $5 \mathrm{~kg}$ stems. The anniversary management measure is the same as the conventional management. There are 10 plants per plot, with 3 repeats and 8 treatments of each village. There are 480 treatments total between the two villages. Table 1 shows the treatment and number.

Observation of phenophase: This is the germination stage in which new shoots grow (starting calculating the new shoot length when it is $25-30 \mathrm{~cm}$ ) and initial flowering and (appearance of 5\% corolla), fruit maturation (95\% fruits become transparent and soft) are recorded.

Determination of fruit yield, the content of total sugar, tartaric acid, tannin, anthocyanin and vitamin $C$ : Three fruit clusters of each plant are obtained, the toll fruit clusters number being 90 . They are weighted and the yield is calculated. Lastly, they are frozen to $-20^{\circ} \mathrm{C}$ to preserve. The method of extracting and determination total soluble sugar of the fruit can be found in the Experiment

Table 1: The treatment of applying basal fertilizer and code

\begin{tabular}{ll}
$\begin{array}{l}\text { Codes of } \\
\text { treatment }\end{array}$ & Treatments \\
\hline A & Stripy furrows fertilizer \\
B & Stripy furrows fertilizer and plastic mulching \\
C & Stripy furrows storing fertilizer and water + plant grass \\
D & Stripy furrows storing fertilizer and water and plastic \\
& mulching \\
E & Two cave fertilizer \\
F & Two cave fertilizer and plastic mulching \\
G & Two cave storing fertilizer and water + plant grass \\
H & Two cave storing fertilizer and water + plastic mulching \\
\hline
\end{tabular}

Handbook of Plant Physiology (Xue and Xia, 1985). Tartaric acid is related to sodium hydroxide titration (Wang, 1999). Tannin in grape peel is related to Folic-Denis reagent. The quantitative method of Anthocyanin is detailed in consults $\mathrm{pH}$-differential spectrophotometer of quantitative spectra analysis (Qin, 1991). Vic is related to 2, 6D (Han, 1992). The data was analyzed using software SPSS.

\section{RESULTS AND DISCUSSION}

The effects of different treatments of basal fertilizer applied technology on phenophase in Cabernet Sauvignon Grape cultivar: Form Table 2, basal fertilizer applied technology in Cabernet Sauvignon grape cultivar advances in phenophase handling (stripy furrows storing fertilizer and water plus plastic mulching), especially advances the most, followed by $\mathrm{H}$, (two cave storing fertilizer and water plus plastic mulching) and B (stripy furrows fertilizer and plastic mulching). Firstly, D advances 9-13 days in germination stage, 9-15 days in new shoot growing stage, 8-10 days in initial flowering stage and 6-9 days in fruit maturation stage. Secondly advances 8-12 days in germination stage, 8-10 days in new shoot growing stage, 5-7 days in initial flowering stage and 5-7 days in fruit maturation stage. Lastly, B advances 2-6 days in germination stage, 4-10 days in new shoot growing stage, 3-5 days in initial flowering stage and 2-5 days in fruit maturation stage.

The effects of different treatments of basal fertilizer applied technology on yield and quality in Cabernet Sauvignon grape cultivar: Form Table 3, basal fertilizer applied technology raises the yield to 1321 $1637 \mathrm{~kg} / 667 \mathrm{~m}^{2}, 16.12-19.66 \%$ higher. D raises the most, reaching $1637 \mathrm{~kg} / 667 \mathrm{~m}^{2}$, with a percentage of $19.66 \%$, followed by $\mathrm{H}$, reaching $1534 \mathrm{~kg} / 667 \mathrm{~m}^{2}$, with a percentage of $16.12 \% \mathrm{E}$ (two cave fertilizer) raises the lowest yield. There are no obvious differences in yield among the other basal fertilizer applied technologies. Besides, D raises the net income by 2800 Yuan per Mu, after exempting 500 Yuan on the cost of straw and plastic film.

Basal fertilizer applied technology in Cabernet Sauvignon grape cultivar makes the total sugar amount to $17.30-20.34 \mathrm{~g} / 100 \mathrm{~g}$ FW; a $0.60-15.57 \%$ D increase. The difference between $\mathrm{H}$ and $\mathrm{B}$ however, is not evident. $\mathrm{E}$ produces the lowest content of total sugar, reaching $17.30 \mathrm{~g} / 100 \mathrm{~g} \mathrm{FW}$. There are no obvious differences in total sugar amount between $\mathrm{E}$ and the other basal fertilizer applied technologies. Tartaric acid amounts to 0.571-0.701 g/100 g FW for basal fertilizer applied technology in Cabernet Sauvignon grape cultivar. This is $10.36-15.55 \%$. 
Agric. J., 5 (2): 70-73, 2010

Table 2: The effect of different treatments on Phenophase in Cabernet Sauvignon Phenophase (day month ${ }^{-1}$ )

\begin{tabular}{lllc} 
Treatments & Germination stage & New shoot growing stage & Initial flowering stage \\
$\mathrm{A}$ & $3 / 4-7 / 4$ & $29 / 4-5 / 5$ & $28 / 5-30 / 5$ \\
$\mathrm{~B}$ & $1 / 4-3 / 4$ & $25 / 4-1 / 5$ & $25 / 5-27 / 5$ \\
$\mathrm{C}$ & $27 / 3-30 / 3$ & $23 / 4-29 / 4$ & $23 / 5-26 / 5$ \\
$\mathrm{D}$ & $25 / 3-27 / 3$ & $20 / 4-25 / 4$ & $20 / 5-24 / 5$ \\
$\mathrm{E}$ & $4 / 4-8 / 4$ & $1 / 5-3 / 5$ & $28 / 5-1 / 6$ \\
$\mathrm{~F}$ & $3 / 4-5 / 4$ & $27 / 4-29 / 4$ & $27 / 5-29 / 5$ \\
$\mathrm{G}$ & $1 / 4-3 / 4$ & $25 / 4-28 / 4$ & $25 / 5-27 / 5$ \\
$\mathrm{H}$ & $27 / 3-29 / 3$ & $23 / 4-25 / 4$ & $23 / 5-25 / 5$ \\
\hline
\end{tabular}

Table 3: The effect of different treatments on yield and quality in Cabernet Sauvignon Yield and quality of Cabemet Sauvignon

\begin{tabular}{|c|c|c|c|c|c|c|}
\hline Treatments & $\begin{array}{l}\text { Yield } \\
\left(\mathrm{kg} / 667 \mathrm{~m}^{2}\right)\end{array}$ & $\begin{array}{l}\text { Total sugar } \\
(\mathrm{g} / 100 \mathrm{~g} \mathrm{FW})\end{array}$ & $\begin{array}{l}\text { Tartaric acid } \\
(\mathrm{g} / 100 \mathrm{~g} \mathrm{FW})\end{array}$ & $\begin{array}{l}\text { Tannin } \\
\left(\mathrm{g} \mathrm{L}^{-1}\right)\end{array}$ & $\begin{array}{l}\text { Anthocyanin } \\
(\mathrm{mg} / 100 \mathrm{~g})\end{array}$ & $\begin{array}{l}\text { Vitamin C } \\
(\mathrm{mg} / 100 \mathrm{gFW})\end{array}$ \\
\hline $\bar{A}$ & $1368 \mathrm{Dd}$ & $17.60 \mathrm{Cc}$ & $0.627 \mathrm{Bb}$ & $0.85 \mathrm{Aa}$ & $65.06 \mathrm{Cc}$ & $5.56 \mathrm{Bb}$ \\
\hline $\mathrm{B}$ & $1420 \mathrm{Cc}$ & $18.30 \mathrm{Bb}$ & $0.603 \mathrm{Bb}$ & $0.83 \mathrm{Aa}$ & $71.39 \mathrm{Bb}$ & $5.62 \mathrm{Bb}$ \\
\hline $\mathrm{C}$ & 1381Dd & $17.43 \mathrm{Cc}$ & $0.701 \mathrm{Aa}$ & $0.89 \mathrm{Aa}$ & $66.74 \mathrm{Cc}$ & $6.21 \mathrm{Aa}$ \\
\hline $\mathrm{D}$ & $1637 \mathrm{Aa}$ & $20.34 \mathrm{Aa}$ & $0.592 \mathrm{Bb}$ & $0.73 \mathrm{Bb}$ & $78.32 \mathrm{Aa}$ & $6.29 \mathrm{Aa}$ \\
\hline $\mathrm{E}$ & $1321 \mathrm{Ee}$ & $17.30 \mathrm{Cc}$ & $0.694 \mathrm{Aa}$ & $0.88 \mathrm{Aa}$ & $64.30 \mathrm{Cc}$ & $5.69 \mathrm{Bb}$ \\
\hline $\mathrm{F}$ & $1358 \mathrm{Dd}$ & $17.80 \mathrm{Cc}$ & $0.611 \mathrm{Bb}$ & $0.86 \mathrm{Aa}$ & $70.34 \mathrm{Bb}$ & $6.08 \mathrm{Aa}$ \\
\hline G & $1387 \mathrm{Dd}$ & $17.60 \mathrm{Cc}$ & $0.637 \mathrm{Bb}$ & $0.88 \mathrm{Aa}$ & $63.45 \mathrm{Cc}$ & $5.73 \mathrm{Bb}$ \\
\hline$\underline{\mathrm{H}}$ & $1534 \mathrm{Bb}$ & $18.96 \mathrm{Bb}$ & $0.571 \mathrm{Cc}$ & $0.75 \mathrm{Bb}$ & $73.40 \mathrm{Bb}$ & $6.13 \mathrm{Aa}$ \\
\hline
\end{tabular}

D decline, with decreasing is $15.55 \%$. $\mathrm{E}$ and $\mathrm{G}$, however (two cave storing fertilizer and water plus plant grass) produce the highest tartaric acid content, respectively reaching $0.694 \mathrm{~g} / 100 \mathrm{~g} \mathrm{FW}, 0.701 \mathrm{~g} / 100 \mathrm{~g} \mathrm{FW}$. There were no evident differences between them, nor any obvious differences in tartaric acid content among the other basal fertilizer applied technologies.

Basal fertilizer applied technology in Cabernet Sauvignon grape cultivar make tannin amount to $0.73-0.89 \mathrm{~g} \mathrm{~L}^{-1} \mathrm{D}$ and $\mathrm{H}$ produce the lowest amount, 0.73 and $0.75 \mathrm{~g} \mathrm{~L}^{-1}$, respectively. There are no evident differences between them. Furthermore, there are no obvious differences in tannin amount among the other basal fertilizer applied technologies.

Basal fertilizer applied technology in Cabernet Sauvignon Grape cultivar make anthocyanin amount to $63.45-78.32 \mathrm{mg} / 100 \mathrm{~g} \mathrm{D}$ produces the highest amount, reaching $78.32 \mathrm{mg} / 100 \mathrm{~g}$ followed by $\mathrm{B}, \mathrm{F}$ (two cave fertilizers and plastic mulching) and $\mathrm{H}$. There are no evident differences among them. Furthermore, there are no obvious differences in anthocyanin amount among the other basal fertilizer applied technologies.

Basal fertilizer applied technology in Cabernet Sauvignon grape cultivar make Vitamin $\mathrm{C}$ amount to 5.56-6.29 mg/100 g FW C (stripy furrows storing fertilizer and water plus plant grass), $\mathrm{D}, \mathrm{F}$ and $\mathrm{H}$ produce the higher than the others. There are no evident differences among them. Furthermore, there are no obvious differences in vitamin $\mathrm{C}$ amount among the other basal fertilizer applied technologies. Basal fertilizer which contains various elements, such as $\mathrm{N}, \mathrm{P}, \mathrm{K}$ when applied to grape in autumn, is very advantageous to add nutrition to grape, recover tree structure, improve the capacity of passing winter, benefit the coloration, raise the sugar content and reduce the acid content. The sufficiency and balance of basal fertilizer are the keys to ensuring the nutrition balance of grape. The cave storing fertilizer and water applying fertilizer can save $30 \%$ of the fertilizer, $70 \sim 90 \%$ of the water and raise the income by about 2800 Yuan per $\mathrm{Mu}$, which is of great important significance under the situation of lacking fertilizer and water in the arid and semi-arid habitat in the upstream of the Min River.

The results of this research show that the effect of the cave storing fertilizer and water with stripy furrows is better than that of two cave storing fertilizer and water, which is the same as the Wang (1999) research, Stripy furrows cave storing fertilizer and water and plastic mulching is consistent with Pang Shoutan's (Pang, 1998) research of using the plastic mulching in the apple field, which can greatly raise the production and quality and with Yang Hongqiang's research of using that cave storing fertilizer and water on the apricot tree, which can raise the production obviously.

\section{CONCLUSION}

Cave storing fertilizer and water is done by applying fertilizer to apples. Nutritious and plastic mulching is to put the watering, applying fertilizer and keeping wet together, to create a good environment for the root 
development in a partial scope, so that the fruit trees can grow and bear fruit and raise the production. Using the plastic mulching to store nutritious water can not only save water and fertilizer but also reduce hoeing weeds halfway. The proportion between input and output is $1: 20$ and the effect of raising production is obvious and the method will be used gradually on the fruit trees such as grape trees. The time of using plastic mulching is not the same according to different kinds and habitats, which will be researched later to establish a technique system of cave storing fertilizer and water in grape.

\section{ACKNOWLEDGEMENTS}

The financial support of the National Xinghuo Project (2008GA810007) and Sichuan Agricultural University Innovation Team Program are gratefully acknowledged.

\section{REFERENCES}

Han, Y.S., 1992. The Guide of Food Chemistry Experiment Guide of Food. Beijing Agricultural University Express, Beijing.

Pang, S.T., 1998. The effect of plastic mulching and cave storing nutritious water applied technology on growth of apple trees. Yantai Fruit Trees, 2: 25-26.

Qin, H.Z., 1991. Grape Wine Analytical Chemistry. China's Light Industry Press, Beijing.

Wang, H., 1999. Test Technology and Operating Rules of Grape and Wine. Xian Cartographic Publishing House, Xian.

Xue, Y.L. and Z. Xia, 1985. The Handbook of Plant Physiology Experiment. Shanghai Science Technique Press, Shanghai, China. 